ISSN: 2576-2141

\title{
Body-Worn Cameras and Internal Accountability at a Police Agency
}

\author{
Marthinus Koen ${ }^{1} \&$ Brooke Mathna ${ }^{2}$ \\ University of Southern Indiana
}

\begin{abstract}
Existing research on body-worn cameras have primarily focused on certain policing outcomes (e.g., citizen complaints and use-of-force), however, only a handful of research to date has considered how the implementation of body-worn cameras have impacted internal organizational processes at police departments. Using semi-structured interviews, a survey, and ride-along observations, we examined how body-worn cameras impacted the way police officers were held or felt accountable for their behavior. The study was conducted at the Sunnyvale Police Department (pseudonym), a small city agency in the United States that had been using cameras for two and a half years. Particularly, we describe how body-worn cameras impacted accountability at Sunnyvale within different organizational contexts that included reporting, citizen interactions, training, and supervision. Consistent with the hopes of reformers, body-worn cameras did seem to raise the general sense of accountability as they became a part of training, citizen encounters, reporting, and supervision. However, these changes were not like reformers would have imagined, as the department did not intently use cameras in a way to hold officers any more accountable for their conduct and performance on the street.
\end{abstract}

KEYWORDS: Police Accountability, Police Technology, Body-Worn Cameras.

\section{Introduction}

With the widespread use of smartphones in conjunction with social media, the last decade has marked a change in the way that people communicate, share, and receive information. It is therefore unsurprising that police actions, which had traditionally been imperceptible (Goldstein, 1960), had not only become more visible to the public, but also more widespread. With the increased diffusion and technical improvement of social media, police behavior has steadily become more visible to and has drawn public scrutiny to reported instances of questionable or nefarious police actions.

Some recent examples include the shooting deaths of Michael Brown, Philando Castile, and Tamir Rice. These cases involved the deaths of unarmed black men at the hands of the police. Not only is this detrimental to already fragile police-minority community relations, but in many of these cases, the evidence regarding the particulars of each case had been unclear, which has added to the tensions between the police and the public (Coudert, Butin, \& Le Matayer, 2015). Consequently,

\footnotetext{
${ }^{1}$ Corresponding author: mkoen@usi.edu

2 bmathna@usi.edu
} 
public outcry eventually led to rioting and violence (Koen \& Willis, 2017) and police reform discourse would switch to issues of police accountability and transparency.

The public and policy makers have demanded there be changes in the way the police are held accountable for their behavior. While many suggestions have been made on how to improve police accountability, one of the popular solutions to this perceived problem was the implementation of body-worn cameras (Miller, Toliver, \& PERF, 2014). In fact, shortly after the death of Michael Brown, in attempts to improve relations with the public, the Ferguson Police Department implemented body cameras to help ensure accountability and transparency and to address future conflicts in witness accounts (Koen \& Willis, 2017). Furthermore, the President's Task Force on $21^{\text {st }}$ Century Policing (2015) promoted the potential of body cameras to improve accountability and transparency and subsequently the federal government has made about $\$ 40$ million available to help police agencies pilot and implement body-worn cameras (White \& Coldren, 2017). Implementing body-worn cameras has become increasingly popular as small and large departments across the United States and internationally continue to pilot and implement them (Koen, Willis, \& Mastrofski, 2018; Lum, Stoltz, Koper, \& Scherer, 2019; Strom, 2017).

To some extent the term "body-worn cameras" has become virtually synonymous with "accountability." Proponents of body-worn cameras purport that they can be used to hold officers accountable for their behavior by making their actions more transparent to others (Coudert et al., 2015; Cubitt, Lesic, Myers, \& Corry, 2017; Harris, 2010; Ortiz, 2018; Tankebe \& Ariel, 2016; White, 2014; Scheindlin \& Manning, 2015) and therefore officers become more self-aware (Ariel et al., 2016b). The assumption is that the "awareness of being videotaped leads to transparency, and transparency leads to accountability; ergo, greater awareness leads to increased police accountability (Ariel et al., 2016b, p. 305)". Moreover, others argue that body-worn cameras and the resulting footage can be a conduit for improving officers' performance and conduct on the street (Koen et al., 2018; Voigt et al., 2017; Willis \& Mastrofksi, 2017).

Several randomized controlled trials have studied body-worn camera impacts on accountability indirectly focusing on police outcomes such as complaints and use-of-force and found that body-worn cameras can reduce citizen complaints and have mixed impacts on use-offorce incidents (Ariel \& Farrar, 2012; Ariel et al., 2015, 2016a, 2016c, 2017a, 2017b; Braga et al., 2018). This research also indicated that body-worn cameras have the strongest impacts on these outcomes when departments implemented mandatory activation policies (Ariel et al., 2017b), when officers gave verbal warnings to citizens that the encounter is being recorded, and, when threat of having one's footage reviewed must be "actualized."

Other research like that conducted by Voigt et al. (2017), who reviewed body-worn camera footage in Oakland, CA, considered how respectful officers were when they spoke to citizens belonging to different racial and age groups. Voigt and colleagues analyzed footage related to 981 routine traffic stops conducted by about 250 officers. They found that police officers used more "respectful" language when they interacted with white people and less respectful language when they interacted with black people. If body-worn cameras, in this case had impacted the way police felt for their behavior on the street and the way they interacted with people on the street, there would have likely been no difference in the way that officers interacted with people belonging to different racial groups.

While these studies have considered important outcomes relevant to the discussion of bodyworn cameras and police accountability, these studies have done so indirectly (Lum, Koper, Merola, Scherer, \& Reious, 2015). Some questions that still linger regarding this technology and their impact on accountability. That is: "are police agencies using body-worn cameras and the 
resulting footage with the intent of holding officers any more accountable for their conduct and performance than before?"

Moreover, body-worn cameras can potentially shed light on additional aspects of policing that go beyond citizen encounters have not yet been considered like training and report writing (Koen, 2016; Koen et al., 2018). Therefore, the purpose of this study is to directly examine to what extent body-worn cameras were used at a single police agency to hold officers accountable for their performance and conduct, if at all. More specifically, we explain how body cameras impacted accountability across four key organizational features that include training, report writing, supervision, and citizen encounters. In what follows we consider some literature regarding the impacts of information technology on organizational change, discuss our research site and methods before we present our findings and conclude our paper.

\section{The Diffusion of Body-Worn Cameras}

Since body-worn cameras were catapulted into mainstream discourse, they have diffused rapidly across large and small police agencies in the United States, with smaller agencies being more likely to adopt them (Strom, 2017; Lum et al., 2019). In 2013, LEMAS data indicated that about a third of U.S. police agencies had been using some form of on-officer video system on their first-line officers (Bureau of Justice Statistics, 2013). When the LEMAS was adjusted to add a body-worn camera supplement in 2016, the data showed that about half of sheriff's offices and $60 \%$ of police departments had fully adopted body-worn cameras (Hyland, 2018), with even more planning on piloting the technology in the near future (Lum et al., 2019).

Rogers' (2003) “Diffusion of Innovations” lends insights into why body-worn cameras have been proliferating across police agencies in recent years. While factors such as decision type, communication channels, the nature of a social system, and promotional efforts all impact the rate of adoption of an innovation, Rogers (2003) explained that attributes of an innovation tend to be responsible for the lion's share of variance in the spread of innovations. Given the current limited state of existing research on body-worn camera diffusion and Rogers' claims, we focus predominantly on innovational attributes to understand the rate of adoption of this technology.

Relative advantage pertains to the extent that an innovation is thought to be better than previous practices or ideas (Rogers, 2003). Body-worn cameras stand to offer significant relative advantage to police agencies in terms of time savings, immediate rewards, and improve social prestige as the footage from the devices could improve community relations, documentation, training, and complaints investigations (Koen et al., 2018; Koen \& Willis, 2019; Lum et al., 2019; White, 2014). For example, when a citizen brings a complaint to a police agency, internal investigations can last for quite some time as internal affairs investigators collect evidence and interview all relevant parties (Koen et al., 2018). Body-worn camera footage could allow quick insights into what occurred during a citizen encounter and help speed up complaint investigations (Goodall, 2007; Koen et al., 2018) therefore allowing relative advantage over the way complaint investigations had traditionally been approached.

Second, Rogers (2003) explained that the compatibility of an innovation to values, previous paradigms, and/or needs is related to whether it will be adopted by individuals or organizations. The more compatible an innovation, the more likely that innovation is to be adopted by social entities (Rogers, 2003). In the case of body-worn cameras, this technology addresses a need for police agencies who seek to improve transparency and community relations in an environment that has been critical of the police (Coudert et al., 2015; Cubitt et al., 2017; Harris, 2010; Tankebe \& Ariel, 2016; White, 2014). Research suggest that citizens are generally in favor of police body- 
worn cameras whether they are community stakeholders or "frequent-flyers" (Taylor, Lee, Willis, \& Gannoni, 2017; Todak, Gaub, \& White, 2018) as the presence of the cameras (if recording) make citizen encounters more transparent and thus can help ensure that individual, citizen rights are protected (Koen et al., 2018; White et al., 2017).

While not as important as relative advantage, Rogers (2003) asserts that the perceived complexity of an innovation can also impact its rate of adoption. If a technology is straightforward and can be navigated with relative ease, it is more likely to be adopted, this is especially true if it is in the form of hardware (Rogers, 2003), much like body-worn cameras. Perceptual studies regarding body-worn cameras have found that police officers, for the most part, find body-worn cameras to be easy to use (Gaub, Choate, Todak, Katz, \& White, 2016; Koen \& Willis, 2019; Lum et al., 2019).

Trialability according to Rogers (2003) refers to the extent to which adopters can test an innovation before full implementation. Typically, if it is possible to first use an innovation on a trial basis, it can reduce uncertainty for implementers as it allows for insights of how the innovation might work in their own conditions (Rogers, 2003). Body-worn cameras could very well be considered an innovation with much trialability as many body camera producers offer free trial periods, pilot programs, and beta testing for police agencies. However, police agencies have also received much incentive from the federal government to help pay for pilot programs as approximately $\$ 40$ million has been made available to help police agencies pilot and implement body-worn cameras (Lum et al., 2019; White \& Coldren, 2017).

Lastly, Rogers (2003) posits that the extent to which people can see the results of an innovation, or observability, can affect the rate at which that innovation diffuses across a social network. The impacts of body-worn cameras have been rather resounding, especially in terms of reductions in citizen complaints and is especially an outcome that police managers have emphasized (Koen \& Willis, 2019). Lum et al. (2019) in their systematic review identified 18 experimental or quasi-experimental studies that have investigated body-worn camera impacts on citizen complaint statistics since 2012 found that this technology is related to fewer citizen complaints. While it is unclear exactly what about the cameras are causing these reductions in citizen complaints (Lum at al., 2019), they are typically well-received by police organizations who include these statistics in their annual reports.

\section{Technology and Organizational Change}

Body-worn cameras have been considered a popular source of potential police reform by scholars and policy makers (Miller et al., 2014; Koen \& Willis, 2017; Pew Research Center, 2017), which is unsurprising as new technology has long been considered a solution to social and organizational problems (Marx \& Guzik, 2017). Seeing body-worn cameras as a source of eventual change falls in line with the techno-deterministic point of view information technology ${ }^{1}$ on organizations, which states that new technologies can drive changes in social structures and practices (Deilbert, 1997; Mastrofski \& Willis, 2010; McLuhan, 1964; Meijer \& Thaens, 2013; Willis, 2019).

Information technology, according to this perspective, can enhance police efficiency and effectiveness and therefore be a spring of meaningful change (Boudreau \& Robey, 2005; Ericson \& Haggerty, 1997; Harris, 2007; Meehan, 1998). Some examples of improved outcomes are faster reporting processes, improved data access and management (Groff \& McEwan, 2008), improved call response times (Colton, 1980), and improved officer-to-officer communication (Agrawal, Rao, $\&$ Sanders, 2003). Within this paradigm, body-worn cameras could be a harbinger of change in 
how police officers are held accountable internally. For instance, supervisors or commanders might proactively review patrol footage to assess behavior and performance. In turn, officers might change the way they communicate with the public by exercising verbal caution (Coldren, 2015) or become more dogmatic when interpreting the law as to not show favoritism to certain citizens (Ready \& Young, 2015). Furthermore, body-worn camera footage might become an important training tool, where footage is used to provide context rich examples of situations officers encounter daily (Willis \& Mastrofski, 2017).

Other scholars like Peter Manning (1992a, 1992b, 2013, 2014), fall within the sociodeterministic view and are skeptical of the ability of new technology to be an augury of change (Meijer \& Thaens, 2013). While new technologies might facilitate opportunities for change, the organizations determine how a technology is used (Mastrofski \& Willis, 2010. Thus, existing practices can encumber how technology is used as intended and are instead used in ways that fit best with the existing structures and practices of an organization (Colton, 1978; Koper, Taylor, \& Woods, 2013; Lum, Hibdon, Cave, Koper, \& Merola, 2011; Manning, 1992b, 1996, 2013, 2014; Willis, Mastrofski, \& Weisburd, 2004). If a technology demands that agency members to drastically change the way they behave, existing organizational structures and practices that are entrenched in the standard policing model can lead to the misuse, abuse, unintended consequences, or abandonment of that technology altogether. This has especially been the case when new technologies have demanded organizations take on more proactive or problem oriented policing approaches (Manning, 1992a, 1992b, 2013).

In the case of body-cameras for example, officers might claim to lose SD cards with important footage on it or perhaps officers "forget" to turn on the cameras during important citizen interactions. Officers in charge of maintaining or handling the footage, might delete, never review, or edit it. Police managers might not require that footage is reviewed or be a part of officer evaluations, or implement other "toothless" policies (see Ariel et al., 2016b) that leave to officers to choose when to turn on the cameras or might not strictly enforce mandatory camera usage policies. In this case, the implementation of body-worn cameras would simply be a pretense of increased internal accountability.

A third perspective, postulates that certain technologies may change certain organizational features more than others but that technologies mostly tend to be used in ways that fit with existing organizational strategies (Chan, 2001, 2003, 2007; Willis, 2019; Willis, Koper, \& Lum, 2018; Willis, Mastrofski, \& Weisburd, 2007; Meijer \& Thaens, 2013). Neither the technology nor the organization has absolute power over how technology will be used, but certain aspects of organizational life are more susceptible to change with the adoption of new technologies than others (Mastrofski \& Willis, 2010). For example, Lum, Koper, and Willis (2016) note that police officers tend to put much emphasis on technologies that make their day-to-day behaviors more efficient:

When technologies are introduced that are not regarded as efficient or do not contribute to what officers believe to be their primary task, then those technologies are resisted, even if their use may make officers more effective.

Changes with new technology can occur, but not always as innovators might anticipate (Mastrofski \& Willis, 2010; Willis et al., 2018).

Mastrofski \& Willis (2010) explain that changing these old organizational practices and structures might take longer than expected as older generations of officers are replaced by new 
ones. Therefore, body-worn cameras would have an uneven impact on internal accountability, in some cases body-worn cameras would be unable to outclass strongly entrenched aspects of police culture. Body camera footage might be used to help enhance traditional evidence collection practices during investigations, officers might review footage to help them write more accurate reports, or supervisors might use the footage to investigate citizen complaints. However, at the same time, body cameras would not be used in a way to significantly change the way that officers are trained or evaluated for their performance and conduct on the street (Koen et al., 2018).

Ariel et al. (2016b, 2017b) suggest that the way body-worn cameras impact accountability could depend on their implementation. If body-worn cameras were to significantly change accountability in the way that proponents would imagine, it would need to be accompanied by significant organizational change. Therefore, the purpose of this study is to describe and understand how body-worn cameras have impacted the internal accountability process at one small police agency in the United States overtime. In what follows we describe our research site and design, present our findings, and acknowledge the limitations of our methods before we conclude our paper.

\section{Research Site}

Data collection for this study commenced in the Summer of 2015 and lasted four months. Since we lacked the resources to study a police agency before, during, and after the implementation of body-worn cameras, one major canon for selecting a study site was that the agency had already implemented and used body-worn cameras for more than a year. This would allow officers to effectively remember the implementation process and changes that might have occurred and would also have allowed for enough time to pass for the organization to overcome any initial struggles associated with the implementation of a new technology (Rossi \& Freeman 2004). The study was conducted with the Sunnyvale Police Department (pseudonym), a small city agency in the United States that had been using cameras for two and a half years when field work started.

According to the Uniform Crime Reports (2015), the City of Sunnyvale consisted mostly of a suburban population of roughly 25,000 people with $10 \%$ living under the poverty line. The racial composition of the city was about half Black and $20 \%$ White, with the remaining population divided virtually equally between Latino and Asian individuals. Its violent crime and property crime rates were both above the national crime rates for cities of its size.

Sunnyvale equipped its officers with Axon Flex, head-mounted cameras which were rolled out in annual stages for financial reasons. The department contracted Evidence.com for cloudbased data storage which offered two ways for Sunnyvale officers to access footage. With "user" access, supervisors, detectives, and patrol officers could review footage from their own devices, but users could not view footage belonging to others. "Administrator" status was delegated to commanders and "retention officers. ${ }^{2 "}$ Administrators could view any officer's footage, share it between officers, grant access to it, mark it for deletion, and copy footage onto DVDs for evidence. When someone with user access desired footage from another officer, s/he had to send an email request to one of the retention officers to obtain that footage. It is important to consider that, only one of the five first-line supervisors had Administrator access to camera footage due to their designation as a retention officer ${ }^{3}$. Footage was generally retained for six months, unless it had been labelled by an officer with a case number, and then it could be kept indefinitely or until the case had been resolved.

\section{Research Design}


Given the purpose of this research, our sample was purposive as we included officers across the organization that were in some way involved with body-worn cameras (e.g., wearing them, implementation, review of footage). Our sampling frame comprised 45 police officers across all ranks, 26 of whom were patrol officers. These officers' involvement in body-worn cameras spanned from being part of the implementation process, review of footage, training, maintenance, and wearing them during citizen encounters. Of these 45 officers, 38 (84\%) participated in the study (including 23 of all 26 patrol officers) ${ }^{4}$. All participating officers had been at Sunnyvale for longer than 3 years and thus could speak to the changes that had occurred following the implementation of body-worn cameras.

Our data primarily consisted of semi-structured interviews (comprising approximately 15 questions each) which were audio-recorded and later transcribed. Interview guides were generated for officers across the organization (patrol officers, supervisors, command staff, retention officers, investigators, and the chief) and questions tailored to the rank, responsibilities, interviewees' relationship to body-worn cameras, and their thoughts and experiences regarding the technology over time. This format allowed enough structure to ensure consistency among responses while at the same time offering flexibility to explore topics that were not initially anticipated (Patton, 1987). On average, each interview lasted 40 minutes. Participation in the study was voluntary and all interviewees (aside from the chief) were guaranteed confidentiality. Our analysis relies primarily on these data, however, where appropriate we include findings from a patrol officer survey and ride-along observations.

At the end of the interview, the 23 patrol officers were asked to complete a short electronic survey on a 4G-connected tablet. All 23 of these officers agreed to complete the short, electronic survey and it included 39 Likert-style questions inquiring about these officers' perceptions and experiences with body-worn cameras. These data could be cross-referenced with demographic data to provide further context for our qualitative data.

In addition to learning about officers' viewpoints and experiences with body-worn cameras through asking questions, we also solicited those 23 patrol officers who were interviewed and surveyed, to be accompanied during one of their regular patrol shifts for ride-along observations. Nineteen of these accepted requests for a ride-along field observation and lasted about 2 hours each. Ride-alongs also provided an opportunity to ask additional follow-up questions through an additional semi-structured interview guide. Furthermore, observations also occurred during inservice training and a DUI checkpoint (as we learned body cameras were being used in these contexts).

Coding of interview transcripts and field notes proceeded inductively using the software program Atlas.ti (Muhr, 1991). During the first round of coding, data were clustered into broad themes regarding how officers perceived and used body-worn cameras in different aspects of their work (e.g., reporting, discretion, training, supervision) to develop a start list. Transcripts were subsequently re-read several more times and this list was further refined with the creation of subcodes to help identify and classify meaningful patterns in the data (Strauss \& Corbin, 1998; Miles, Huberman, \& Saldaña, 2014). As a check on the validity of our findings, we shared a copy of the report on which this research is based with Sunnyvale's leadership and received no suggested revisions.

Since this is a case study that occurred at a single police agency, it is imperative that the findings and discussion to follow be understood within this context. Despite finding no evidence to believe that Sunnyvale is distinctly unalike other local law enforcement agencies in the United States, we do not intend to make generalizable assertions about body-worn cameras. Instead we 
offer an in-depth, ideographic and variable-oriented examination of the implementation of bodyworn cameras and their impacts on internal accountability that we hope offers useful context to understanding and furthering the existing body camera research.

\section{Findings: Body-Worn Camera Impacts on Accountability}

Nineteen of the 23 patrol officers claimed on the survey that the implementation of bodyworn cameras had made them feel more accountable for their behavior and performance. Similarly, other officers across the organizational also supported this view. Our interview data showed that body cameras had become a part of four aspects of the organization that were related to accountability including training, citizen encounters, reporting, and supervision. We describe how body-worn cameras had been integrated into these organizational features and explain the different ways body cameras had changed how officers were held accountable for their behavior within these contexts.

\section{Training}

Body-worn camera scholars have made similar claims regarding the potential of body-worn cameras being a potential training tool that could provide context rich insights to training officers (White, 2014; Willis \& Mastrofski, 2016, 2017). While the command staff explained that improved training was one of the reasons for implementing body-worn cameras, it seemed that Sunnyvale primarily used body-worn cameras to document officer performance during training exercises (e.g., in-service, field, and remedial training). Per departmental policy, retention officers were required to use body-worn cameras during training sessions and store all training footage on Evidence.com. Each Sunnyvale officer had a separate "training folder" in Evidence.com linked to them that was only accessible to retention officers and to command staff. A retention officer explained why the department was using footage in this capacity:

We record our training to monitor how the officers performed. If somebody performs sub-par or there's some concerns about poor performance in training, you've got that on video to show it to commanders who are typically not [present during] training.

If an officer performed poorly during in-service training, or field training; they were recommended for remedial training. In the case of Sunnyvale, the recorded footage was used to justify such official action. In certain cases when an officer continued to struggle with something, the collection of footage had been used as evidence to terminate the officer and protect the department from any potential lawsuits for wrongful termination.

One officer, we videotaped all his scenarios and he wasn't cutting it. We're like, "Alright, man, you need to make a decision. Do you really want to do this or not?" We wrote up our report that we were going to give to the state's attorney: "This is recorded." Everything was recorded with the body-worn camera. They see that and they're like: "Alright, I'm not going to be sitting here with he said, she said information. This is all on video, so maybe I should just do what I need to do." [Retention Officer 2] 
Prior to the implementation of body-worn cameras, as the officer explained above, what happened during training sessions was difficult to prove as reports depended on training officers' testimony. In this case, body-worn cameras brought transparency to various training contexts and empowered the department to hold officers accountable for their performance during these exercises. All 38 participating officers acknowledged that body camera footage was used in such a capacity.

\section{Reporting}

Sherman (2013) explained that body-worn cameras can become a vital part in the report writing process for police as the devices can record every encounter with the public. He postulated that body-worn cameras may eventually replace written reports as the footage can be used as a "logbook" of police exploits. While body-worn camera footage had not replaced reports at Sunnyvale, the body camera policy required officers to record all encounters with citizens related to any police service (e.g., calls for service and enforcement actions) ${ }^{5}$. This made a lot of footage available to officers to incorporate into their reports and therefore it was unsurprising that all 23 patrol officers claimed on the survey to review footage while writing police reports.

Interestingly, however, 21 of these 23 patrol officers indicated on the patrol survey that they had not changed "the way" that they reported their activities. Interview data provided additional insights and reconciled these seemingly opposing depictions of reporting behavior. Patrol officers $(19 / 23)$ explained that they would spend extra time writing reports and reviewing footage to ensure they included all necessary details to ensure that their reports were accurate. At the same time, these officers were clear that this was not true for all cases and that the complexity of a case typically dictated whether they would take the time to access and review the footage when they wrote their reports.

It just depends on how complicated it was. Usually with cases where a lot of things happen all at once, you know? When there is a fight or something. When you go in autopilot mode, where the adrenaline is pumping, and you are just fighting or whatever. That is when it is good to look at the footage and recap what happened to make sure you have a good report. That video will be looked at, you know? It leaves less chance for a defense attorney to rip you apart. [Patrol Officer 1]

The cases that they considered "complex" enough to warrant referencing body-worn camera footage when filling out police reports included driving under the influence of alcohol or drugs (mentioned by 23/23 patrol officers), incidents involving multiple offenses (21/23), failure to comply offenses (16/23), automobile accidents (16/23), assaults (23/23), or when an officer had to use force (23/23). These officers stressed that these were the types of cases where their footage would likely be reviewed by someone from within or outside of the department and could be compared to their reports.

...once the lawyers get involved and they are meticulously viewing these videos. If someone quoted that someone said something, but they didn't, or it was a little bit off, then it comes into question. Whereas before that really wouldn't have been an issue, but now that we have documented video and 
audio evidence of what the victim or suspect actually said. It certainly leads to more scrutiny in our reports, whether it is the court or [my sergeant]. [Patrol Officer 2]

Moreover all 5 of the patrol supervisors told that they occasionally reviewed subordinate officers' footage to compare to their reports when serious felony charges were going to be filed against a person, which was consistent with patrol sentiments.

While policy did not require officers consult footage when writing reports, the footage allowed people from inside of the organization or outside of it to view footage, compare it to an officer's report, and scrutinize the veracity of their reports. Body camera footage thus made police reports more transparent to others which in turn made officers feel more accountable for their reports. However, it was only relevant to complex cases (e.g., DUI, car accidents, use-of-force, assault, and multiple offense incidents) as these would likely be the instances others would be inclined to review.

\section{Police-citizen encounters}

Traditionally, patrol officer discretion during citizen encounters have been virtually invisible to the public and superior officers (Goldstein, 1960). In addition, Mastrofski (2004) noted that patrol officers therefore have considerable scope in deciding which course of action to take during interactions with citizens (e.g. arrest, citations, verbal warning). Within the context of police decision making, the body-worn camera research has been primarily centered around how these devices impact officers' decisions to use-force, make arrests, write citations, and attentiveness of citizens' rights, and professionalism (Harris 2010; Pew Research Center, 2017; Ready \& Young 2015; Voight et al., 2017; White 2014). While this literature has made invaluable contributions to the collective understanding of body-worn cameras given that patrol officers are the gate-keepers of the system, the current study was centered around learning from the officers themselves how, if at all, they felt body cameras had changed the way they exercised their discretion in day-to-day encounters with the public.

At Sunnyvale, officers were exceedingly unambiguous that body-worn cameras had not fundamentally changed the way they interacted with citizens and that the technology had an overall uneven impact on this facet of police work. However, 24 of the 38 officers explained that bodyworn cameras changed or held potential to change the way they made decisions during citizen encounters. Some officers explained that they had become more legalistic when deciding to write citations, while others expressed, they became mindful of how they communicated with the public.

According to the patrol officer survey, one of the effects of body cameras was to make about a third of the (8/23) officers more legalistic. These officers indicated body-worn cameras made them less willing to "cut breaks," that is "dispensing less punishment than the law allowed the officer to deliver" (Schafer \& Mastrofski, 2005, p. 226). Similarly, over half (14/23) of the patrol officers strongly agreed or agreed with the statement, "I feel like I have to follow the letter of the law when wearing my body-worn camera" on the patrol survey. Our interview data, however, clearly suggested that this apparent legalism associated with body cameras, only corresponded with petty offenses or misdemeanors. This was primarily because departmental policy already allowed less discretionary scope for more serious offenses (e.g. domestic assault).

Patrol officers explained this change was largely because the cameras made it possible for others, particularly superiors, to examine their choices retrospectively and assess whether it was appropriate given the circumstances. The possibility of increased scrutiny made them more likely 
to write a traffic ticket, instead of giving written warnings or just letting someone off with a "peptalk." Officers like the one quoted below stated that a benefit of ticketing everyone who was pulled over decreased the likelihood of being questioned about whether they were treating people differently, or favoring some groups over others (e.g. race, sex, or social status).

\section{Let's say you wind up pulling over some politician or another officer or something, and you want to give them breaks and that something comes back. When they get pulled over a lot in our jurisdiction and then someone wants to look into that and then [the footage] can make you look bad. [Patrol Officer 3]}

These officers felt that they were vulnerable to the claim of differential treatment because a key limitation of the technology was that they only recorded what transpired (which was open to the interpretation of the viewer) and did not capture the officers internal thought process. They felt that if they issued citations to everyone that committed petty offenses, a reviewer of the footage would be hard-pressed to question their discretion. Moreover, these officers felt that supervisors would likely pry into the body-worn camera recordings of patrolmen and women with the least amount of citation activity. By consistently citing everyone, their actions might be precluded from scrutiny.

A similar portion of officers (13/23) explained that they also changed the way they spoke to members of the public when equipped with a body-worn camera. They felt like they were speaking in front of an audience that could extend beyond the parties involved in the immediate encounter and therefore exercised verbal caution (see Coldren 2015). Patrol Officer 4 explained:

Yes, I guess it's a reminder because you're hearing "peep-peep” and you feel [the camera] on your head. It's there. It's just a reminder of like "hey be appropriate don't say anything dumb. Think about what you're doing.

One way in which $4^{6}$ officers explained they changed the way they interacted with the public was through engaging in what they called "roadside court." They had started relying on their knowledge of case law to diffuse tense situations with citizens. Patrol Officer 5 who was a corporal, explained how body-worn cameras played a role in this context.

Actually, it has changed the way I interact with some people. And I have also seen this in other officers. You know, we try to memorize case law a lot more now. I find myself knowing a lot more case law. This way, when some dummy, gives me shit on the street, I can tell them why I am doing what I am doing. So, I guess, it makes me try to out "law" them.

Consistent with tenets of procedural justice which imply that people distinguish between outcomes and processes and tend to be satisfied with officers even when outcomes are negative when officers explain their actions to them (Skogan, 2005). These few Sunnyvale officers were using their knowledge of case law to explain why they could stop citizens or detain them, which the in the opinions of those officers led to diffusing come tense situations or garnering cooperation.

Sunnyvale officers exercised verbal caution in other ways that included being careful of the veracity of content they conveyed to the public (7/23) and being cognizant of their tone of voice (4/23), however, they were the most concerned with limiting their profanity during these encounters. Patrol officers (8/23) who said that they became more careful of using profanity when 
interacting with the public explained that when citizens filed complaints against them, and the video showed that they were cursing, they would receive disciplinary action from their superiors. Since the camera would have likely caught the profanity during an encounter, superior officers automatically had evidence of profanity, which was against policy. Officers also explained that in high intensity situations or when communicating with a particularly belligerent citizen, it was particularly challenging to control the profanity they used.

In sum, consistent with existing literature on body-worn cameras (Ariel et al., 2015; Goodall, 2007; Katz, Kurtenbach, Choate, \& White, 2015; MPD, 2013), the cameras brought a certain level of transparency to police-citizen interactions that changed the way that the police officers behaved. Due to the possibility that officer footage could be reviewed by others, some officers became more legalistic and/or began to exercise verbal caution when interacting with citizens, however, the impact was uneven as not all had changed their behavior.

\section{Supervision}

Supervision is a multifaceted structure that can occur in a general and at a first-line capacity. "General supervision," refers to any officer overseeing and assessing the conduct and performance of a subordinate or another officer. This can include the chief holding his or her command staff accountable, retention officers concerning over the behavior of patrol officers, or commanders evaluating the behavior of sergeants. However, "first-line supervision" references one type of supervision that involves first-line supervisors (typically sergeants) holding patrol officers accountable for their behavior and quality of work, which comprises oversight, discipline, and guidance. Because of the way that the body-worn camera policy at Sunnyvale mandated the review of the footage, the cameras were relevant within the context of general and first-line supervision. In what follows, we explicitly differentiate between the two when necessary.

Sunnyvale's policy required retention officers and commanders to proactively review footage as it read:

\section{Designated management and retention officers will conduct weekly reviews of videos with proper use or training issue. Designated management and retention officers will report any officer safety issues to a sergeant or commander for remedial training.}

Interview data indicated, however, that while the retention officers did review body camera footage on a weekly basis, commanders did not successfully keep with the policy.

Of the three commanders who participated in the study, only one claimed that they ever reviewed body-worn camera footage. This commander explained that they seldom reviewed footage as their other duties required more of their time. The other commanders who admitted to never reviewing body-worn camera footage, also cited being too busy with other tasks that took priority. More importantly, all 3 commanders iterated an ideological objection to reviewing body camera footage as it could cause unnecessary friction between them and patrol:

I think it is because I got charged a couple times with minor policy infractions when I was using the in-car camera. One time I had a friend do a ride-along with me and I ended up going on a high-speed chase after [a suspect] with the ride-along in the car with me. We are supposed to drop people off at a safe place before we do something like that. But I got 
charged because I took him along. I mean I had to tail this guy and at some point, when I realized that there were five other [police vehicles] with me, I decided to pull off. It just kind of stuck with me and I never was a fan of being video recorded and that is why I am not a fan of watching the [bodyworn camera] video. [Commander 1]

Retention officers on the other hand, did review footage as often as the as the policy mandated. However, this was not entirely as proactive ${ }^{7}$ as the policy implied. These officers spent most of their time reviewing footage when they were conducting administrative duties (e.g., burning DVDs for court) as opposed to seeking out instances of safety and training quandaries. Instead they did take note of such issues when they happened upon them while performing administrative tasks, therefore, making the way they reviewed footage within a supervisory context more "passive."

At the same time, they were reluctant to report most problems that they found to a supervisor like the policy mandated. Retention Officer 2 provided an example:

We don't want to write anybody up, we don't want to get anybody in trouble, but we want to say "hey, we were looking at this. The thing about doing this, it's a better officer safety thing or it's a better thing to keep you out of trouble later."

As a matter of fact, all but one (of the five retention officers) were unambiguous about giving other officers a "heads-up" instead of taking the footage to a supervisor or the command staff. They would choose to informally address conduct and performance issues with officers instead of reporting them to supervisors or command staff.

Sunnyvale's written policy and the limited access sergeants had to footage ${ }^{8}$ portrayed that using this technology to strengthen first-line supervisory control in the agency was not a priority. Ascribed supervisory duties were to make sure that officers had them equipped at rollcall and that they were being used in accordance with departmental regulations. When the policy did ask supervisors to review footage, was in response to complaints from citizens or other officers (e.g., retention officers).

Out of the five supervisors, only two explained that they had at some point since the adoption of body-worn cameras reviewed the footage in a proactive manner. One of these supervisors reviewed body camera footage because they were also a retention officer and did so for administrative purposes. The other supervisor explained that they, on very few occasions reviewed footage to check on a new officer who had been particularly challenged by certain aspects of field-training.

It's pretty random and seldom. It depends on the officer, and it's not necessarily based on the officer being a bad officer. Some officers just have a more difficult time during field training, you know? They make it through by the skin of their teeth. I just like to check in with those officers and see how they are doing. [Supervisor 1]

Proactive review of footage was rare, and when sergeants did review footage, it was mostly reluctant and reactive. Overall, our data revealed that first-line supervisors, much like commanders, did not want to see the footage. They saw body-worn camera footage as a technology that would 
lead to frivolous fault-finding and "Monday-morning quarterbacking" (see Baily \& Bitner, 1984). This was even more evident when all sergeants were granted Administrator access during our last week of fieldwork, as we could ask them how this change had affected them. All agreed that they would not change the way they supervised their patrol officers. These findings are unsurprising given how fragile and fraught with suspicion the relationship between first-line supervisors and patrolwomen and men can be (Brown, 1983).

\section{Discussion}

Similar to the perspective that postulates technological change to impact certain structures and practices more than others, we found that the adoption of body-worn cameras at Sunnyvale had an uneven impact on internal accountability. Consistent with the hopes of reformers, our findings indicate that the implementation of body-worn cameras did influence internal accountability, however, the change was not how proponents of this technology might have imagined. The mere presence of body-worn cameras made it possible to have one's behavior documented and reviewed by people inside or outside of the department, which caused officers to feel generally more accountable for their behavior, which spread across reporting, training, and police-citizen encounters. Thus, accountability stretched in scope. At the same time, Sunnyvale did not intently use body-worn cameras to hold police officers any more accountable for their behavior and therefore, accountability did not increase in intensity.

These findings were unsurprising given the literature concerning institutionalized organizations like police agencies (Mastrofski \& Uchida, 1996). Crank (2003) explained that institutionalized organizations tend to loosely couple formal practices with actual police behavior as it can be beneficial for the department to save face with its constituents who can have conflicting views with the department and each other (e.g., ACLU, FOP, city council, community). Loose coupling allows police organizations to pander to the demands of constituents while allowing organizational members to carry on as usual (Crank, 2003). In the case of Sunnyvale, it seemed that this was the case in how body-worn cameras impacted accountability and was evident in three ways.

First, "Administrator" access to footage on Evidence.com was only given to retention officers and commanders, not supervisors. Body cameras presented supervisors with a unique opportunity to monitor their officers' actions, yet if supervisors wanted to review footage, they had to request it from retention officers. If body-worn cameras had been implemented to serve as an important supervisory tool, supervisors would have likely had "Administrator" access to footage long before the last week of data collection.

Secondly, the way Sunnyvale's body-worn camera policy was written and mandated the review of footage seemed to indicate that there were no intentions to use the technology to intensify accountability. Sunnyvale's body-worn camera policy required commanders and retention officers to peruse the footage for the purposes of finding training material and identifying any safety issues. They were not mandated to look for officer misconduct or monitor the quality of performance. There were also no language outlining repercussions for neglecting to review body camera footage.

Lastly, when footage was reviewed, it was often passive or reactive, and was seldom centered on identifying issues related to officer conduct or performance. When supervisors viewed footage to focus on an officer's quality of performance or conduct, it was primarily done on an asneeded basis in response to complaints. Even with their newly granted access to footage, supervisors were still reluctant to proactively review footage as they did not want to get their subordinates in trouble for minor violations of policy. 


\section{Conclusion}

We admit that our research is not without limitations. Sunnyvale was a small municipal agency, which implies our findings cannot be generalized. However, Sunnyvale was similar to other smaller agencies in the U.S. that are likely to implement body cameras. It was large enough to have specialized units, multi-rank bureaucratic structure, and employed some civilian staff (Reaves, 2015). Moreover, smaller agencies are more likely to implement body cameras than larger ones (Strom, 2017), while most of the body-worn camera research have focused on larger police organizations (Koen \& Willis, 2019).

Furthermore, it is uncertain if reactivity during ride-alongs affected the extent to which patrol officers behaved and made decisions. Mastrofski et al. (1998) found that when proper precautions were taken, like using observational data with other forms of data, this limitation could be overcome. Moreover, much time and effort were put into ensuring that officers were comfortable with our presence and we took precautions to make note of when it seemed like an officer's behavior changed due to our presence during ride-alongs and was a rare occurrence.

Similarly, during semi-structured interviews, social desirability may have impacted the validity of our data. Especially regarding negative information about police behavior, body-worn cameras, or how the organization had been affected by their implementation. Interviewing members of different ranks and organizational groups, in this case, did reduce some of this risk. Survey data was anonymous, and patrol officer respondents may have been more likely to be truthful when answering survey questions since that that did not require them to speak directly to researchers.

Lastly because of resource constraints, our findings relied on officer recollections of events. Police officer perceptions and recollections of how organizational behavior had changed could have been different from how they actually changed (if at all). Conducting a pre-post implementation analysis of body-worn cameras would have likely yielded a more nuanced understanding, of how accountability had changed at Sunnyvale.

Despite these limitations, this work expands on what we know about body-worn cameras and their impacts on outcomes relevant to accountability (e.g., citizen complaints and use-of-force data; see Ariel et al., 2016b, 2017a) through an ideographic examination of how the adoption of this technology impacted the way officers were held or felt accountable for their behavior. This research, therefore, leaves important implications for both practitioners and scholars to take into consideration.

Agencies must be cautious of how they formulate policy and use body-worn cameras for the purposes of accountability as it could open opportunity for tremendous time and resource constraints (Koen et al., 2018) and/or be detrimental to generating or maintaining line-level officer buy-in (Gaub et al., 2016; Koen \& Willis, 2019).

Like Sunnyvale, agencies may also consider using body-worn cameras (if storage capacity allows) to monitor officer performance during in-service and field training to uphold and improve training standards. However, body-worn camera footage can also be leveraged into a training tool, encouraging training officers and line-level supervisors to find examples of best practices and satisfactory police craft (see Willis \& Mastrofski, 2017). Body-worn camera footage offers familiar insights that are relevant to the officers from within their own jurisdictions, during the same shifts they work, with the same people they work with, and the same citizens they encounter. Footage could be useful in a group or individual setting; whether referencing a particular incident with an 
officer; or inspiring, guiding, or complementing in-service training scenarios and training materials.

Many Sunnyvale officers felt compelled to incorporate body camera footage in their reports when they anticipated someone from inside (e.g., higher-ranking officer) or outside of the agency (e.g., attorney) would compare their footage to a report. Police leaders might consider including in their operational guidelines exactly under which circumstances and to what extent officers should incorporate body-worn camera footage into their reports. At Sunnyvale, many, but not all officers referenced footage for cases that they deemed "complex," yet there were no standard inclusion criteria for when a case should fall in this category. If practitioners can use the policy to clarify how to use body-worn camera footage within this context, they could stand to improve and uphold reporting standards.

Future examinations might take similar approaches in understanding how body-worn cameras had been integrated in accountability processes at a variety of other agencies as differences could possible exist based on the size and bureaucratic structure (Maguire, 2003). This would provide serviceable, large-scale insights into how body cameras are used (if at all) to hold police officers accountable for their performance across different contexts that look beyond citizen complaints and use-of-force outcomes.

Furthermore, as all the Sunnyvale patrol officers indicated that they used body-worn camera footage when they wrote reports regarding complex cases. It is important to understand how this is happening at other agencies and which factors (e.g., technical features and functionality, policy, patrol culture) impact the extent to which officers incorporate the footage into their reports. Moreover, since Sunnyvale officers felt that the footage improved the quality of their reports, future research must objectively (and preferably quantitatively) examine to what extent reviewing bodyworn camera footage improves the veracity of police reports.

Large-scale, multi-site, studies may also objectively illuminate whether or to what extent officers have changed the way they interact with or used discretion during citizen encounters. While some research (like this study) has sought to understand these variables by relying on officers' perceptions of their own behavior (Koen \& Willis, 2019; Gaub et al., 2016), very little research has made attempts to do so objectively.

\section{Endnotes}

${ }^{1}$ Since body-worn cameras capture and render digital video and audio data, they have been considered a type of information technology.

${ }^{2}$ These retention officers were field training officers who had received training on other Axon products (e.g., Tasers). Given their history with Axon, the department decided to have these officers go through the Axon Flex and Evidence.com training.

${ }^{3}$ A week before the end of data collection, all first-line supervisors were provided with this access.

${ }^{4}$ Those excluded from the sampling frame were 14 patrol officers who were not yet equipped with a body-worn camera, and non-sworn personnel. None of these subjects had any experience or involvement with body-worn cameras.

${ }^{5}$ We noted only 5/44 times during observations that officers had forgotten to turn on their bodyworn cameras.

${ }^{6} \mathrm{We}$ understand that this is a small portion of officers, however, it is still interesting and should be further investigated in subsequent research. 
7 We define "proactive review" of footage, as reviewing body-worn camera footage without being prompted to do so for any other reason (e.g., burning footage to a DVD; assigning footage belonging to one office to another) than what the policy outlined.

8 The policy delegated preemptive review of footage to retention officers and commanders. Supervisors did not receive Administrator access to the footage until one week before data collection concluded.

\section{Acknowledgements}

The authors would like to thank Dr. James J. Willis for his mentorship through the data collection, analysis, and writing process. We also would like to thank the anonymous reviewers for the comments and suggestions that helped improve this manuscript.

\section{References}

Agrawal, M., Rao, H., \& Sanders, G. (2003). Impact of mobile computing terminals in police work. Journal of Organizational Computing \& Electronic Commerce, 13(2), 73-89.

Ariel, B., Farrar, W. A. (2012). The Rialto Police Department wearable cameras experiment experimental protocol: CRIMPORT. University of Cambridge, Institute of Criminology. Retrieved from http://www.crim.cam.ac.uk/research/experiments/rex-post/rialto.pdf

Ariel, B., Farrar, W. A., \& Sutherland, A. (2015). The effect of police body-worn cameras on use of force and citizens' complaints against the police: A randomized controlled trial. Journal of Quantitative Criminology, 31, 509-535.

Ariel, B., Sutherland, A. Henstock, D., Young, J., \& Sosinski, G. (2017b). The deterrence spectrum: Explaining why police body-worn cameras 'work' or 'backfire' in aggressive police-public encounters, Policing: A Journal of Policy and Practice, 1-21. doi:10.1093/police/paw051

Ariel, B., Sutherland, A. Henstock, D., Young, J., Drover, P., Sykes, J., Megicks, S., \& Henderson, R. (2017a). 'Contagious accountability:' A global randomized controlled trial on the effect of police body-worn cameras on citizens' complaints against the police. Criminal Justice and Behavior, 44, 293-316.

Ariel, B., Sutherland, A., Henstock, D., Young, J., Drover, P., Sykes, J., Magicks, S., \& Henderson, R. (2016a). Wearing body cameras increase assaults against officers and does not reduce police use of force: Results from a global multi-site experiment. European Journal of Criminology, 1-12. doi:10.1177/1477370816643734

Ariel, B., Sutherland, A., Henstock, D., Young, J., Drover, P., Sykes, J., Magicks, S., \& Henderson, R. (2016b). A global multisite randomized controlled trial on the effect of police body-worn cameras on citizens' complaints against the police: A case of contagious accountability? Criminal Justice and Behaviour, 44(2), 293-31.

Ariel, B., Sutherland, A., Henstock, D., Young, J., Drover, P., Sykes, J., Magicks, S., \& Henderson, R. (2016c). Report: Increases in police use of force in the presence of body-worn cameras are driven by officer discretion: A protocol-based subgroup analysis of ten randomized experiments. Journal of Experimental Criminology 12(3), 453-463.

Bayley, D., \& Bittner, E. (1984). Learning the skills of policing. Law and Contemporary Problems, 47, 35-59.

Bourdeau, M., \& Robey, D. (2005). Enacting integrated information technology: A human agency perspective. Organization Science, 16(1). doi:10.1287/orsc.1040.0103 
Braga, A.A., Sousa, W.H., Coldren, Jr., J.R., and Rodriguez, D. (2018). The effects of body-worn cameras on police activity and police-citizen encounters: A randomized controlled trial. Journal of Criminal Law and Criminology, 108(3): 511-538

Brown, M. K. (1983). Working the street: Police discretion and the dilemmas of reform. New York, NY: Russel Sage Foundation.

Bureau of Justice Statistics. (2013). Data collection: Law enforcement management and administrative statistics survey (LEMAS). Washington, DC: Office of Justice Programs, Bureau of Justice Statistics. Retrieved from www.bjs.gov/index.cfm?ty=dcdetail\& iid=248

Chan, J. (2001). The technological game: How information technology is transforming police practice. Criminal Justice, 1(2), 139-159.

Chan, J. (2003). Police and new technologies. Handbook of Policing, 655-79.

Chan, J. (2007). Making sense of police reforms. Theoretical Criminology, 11(3), 323-345.

Coldren, J. (2015, November). "Evaluating the use of body-worn cameras: Randomized control trials in four jurisdictions." Panel discussant, annual conference of the American Society of Criminology. Washington, DC.

Colton, K. (1978). Police computer technology: The case of the San Diego computer-aided dispatch system. Public Productivity Review, 4(1), 21-42.

Coudert, F., Butin, D., \& Le Matayer, D. (2015). Body-worn cameras for police accountability: Opportunities and risks. Computer Law \& Security Review, 31, 749-762

Crank, J. C. (2003) Institutional theory of police: A review of the state of the art. Policing: An International Journal of Policing Strategies \& Management, 26(2), 186-207.

Cubitt T., Lesic R., Myers G., \& Corry R. (2017) Body-worn video: A systematic review of literature. Australian \& New Zealand Journal of Criminology, 50, 379-96.

Deilbert, R. (1997). Parchment, printing and hypermedia. New York, NY: Columbia University Press.

Ericson, R., Haggerty, K. (1997). Policing the risk society. Toronto, ON: University of Toronto Press.

Gaub, J., Choate, D., Todak, N., Katz., \& White, M. (2016). Officer perceptions of body-worn cameras before and after deployment: A study of three departments. Police Quarterly $0(0)$, $1-28$.

Goldstein, J. (1960). Police discretion not to invoke the criminal process: Low-visibility decisions in the administration of justice. The Yale Law Journal, 69(4), 1-11.

Goodall, M. (2007). Guidance for the police use of body-worn devices. Police and Crime Standards Directorate. Home Office of the UK. Retrieved from http://library.college.police.uk/docs/homeoffice/guidance-body-worn-devices.pdf

Groff, E., \& McEwen, T. (2008). Identifying and measuring the effects of information technologies on law enforcement agencies: The making officer redeployment effective program. Institute for Law and Justice Report. Office of Community Oriented Policing Services. U.S. Department of Justice: Washington, DC.

Harris, C. J. (2007). The police and soft technology: How information technology contributes to decision making. In J. Byrne \& D. Rebovich (Eds.), The New Technology of Crime, Law and Social Control (153-183). Monsey, NY: Criminal Justice Press.

Harris, D. (2010). Picture this: Body worn video devices ("head cams") as tools for ensuring Fourth Amendment compliance by police. Legal Studies Research Paper Series. (Working Paper No. 2010-13). Retrieved from http://ssrn.com/abstract=1596901 
Hayes, J., \& Ericson, L. (2012). A Primer on Body-Worn Cameras for Law Enforcement. Washington, DC: U.S. Department of Justice, Office of Justice Programs, National Institute of Justice.

Hyland, S. S. (2018). Body-worn cameras in law enforcement agencies, 2016. Washington, DC: U.S. Department of Justice, Office of Justice Programs, Bureau of Justice Statistics.

Katz, C., Kurtenbach, M., Choate, D. W., \& White, M. D. (2015). Phoenix, Arizona, smart policing initiative: Evaluating the impact of police officer body-worn cameras. Washington, DC: U.S. Department of Justice, Bureau of Justice Assistance.

Koen, M. C., \& Willis, J. J. (2017). Body-worn cameras: The new "normal?" In L. J. Moriarty (Ed.), Criminal justice: Technology in the $21^{\text {st }}$ century (pp. 69-85). Springfield, IL: Charles C. Thomas.

Koen, M. C., \& Willis, J. J. (2019). Making sense of body-worn cameras in a police organization: A technological frames analysis. Police Practice and Research, 1-17, doi:10.1080/15614263.2019.1582343

Koen, M. C., Willis, J. J., \& Mastrofski, S. D. (2018). The effects of body-worn cameras on police organization and practice: a theory-based analysis. Policing and society. doi:10.1080/10439463.2018.1467907

Koen, M.C. (2016). On-set with body worn cameras in a police organization: Structures, practices, and technological frames. (Doctoral dissertation). George Mason University.

Koper, C., Taylor, B., \& Woods, D. (2013). A randomized test of initial and residual deterrence from directed patrols and use of license plate recognition readers at crime hot spots. Journal of Experimental Criminology, 9(2), 213-244.

Lum, C. Koper, C. S., Merola, L. M., Scherer, A., \& Reioux, A. (2015). Existing and ongoing body worn camera research: Knowledge gaps and opportunities. Report for the Laura and John Arnold Foundation. Fairfax, VA: Center for Evidence-Based Crime Policy, George Mason University.

Lum, C., Hibdon, J., Cave, B., Koper, C., \& Merola, L. (2011). License plate reader (LPR) police patrols in crime hot spots: An experimental evaluation in two adjacent jurisdictions. Journal of Experimental Criminology, 7(4), 321-345.

Lum, C., Koper, C., \& Willis, J. (2016). Understanding the limits of technology's impact on police effectiveness. Police Quarterly, O(0), 1-2.

Lum, C., Stoltz, M., Koper, C.S., \& Scherer, J. A. (2019). Research on body-worn cameras: What we know, what we need to know. Criminology and Public Policy, 18(1).

Maguire, E. (2003). Organizational structure in American police agencies: Context, complexity, and control. Albany, NY: State of New York University Press.

Manning, P. K. (1992a). Policing and technology. In N. Morris \& M. Tonry (Eds.), Modern policing (pp. 349-398). Chicago, IL: University of Chicago Press.

Manning, P. K. (1992b). Information technologies and the police. Crime and Justice, 15, 349-39.

Manning, P. K. (1996). Information technology in the police context: The "sailor" phone. Information Systems Research, 7(1), 52-62.

Manning, P. K. (2013). Information technology and police work. In D. Weisburd \& G. Bruinsema (Ed.), Springer encyclopedia of criminology and criminal justice, (pp. 2501-2513). New York, NY: Springer Publishing.

Manning, P.K., 2014. Information Technology and Police Work," in D Weisburd \& G Bruinsema, (eds.), Springer Encyclopedia of Criminology and Criminal Justice (pp 2501-13). New York, NY: Springer Publishing 
Marx, G.T., and Guzik, K., 2017. The uncertainty principle: Qualification, contingency and fluidity in social control. In M.R. McGuire and T.J. Holt (eds.), The Routledge handbook of technology, crime and justice (pp. 481-502). London: Routledge.

Mastrofski, S. D. (2004). Controlling street-level discretion. The Annals of the American Academy of Political and Social Science 593, 100-118.

Mastrofski, S., \& Uchida, C. (1996). Transforming the police. In B. Hancock \& P. Sharp (Eds.), Public policy: Crime and criminal justice (pp. 196-221), Upper Saddle River, NJ: PrenticeHall.

Mastrofski, S., \& Willis, J. (2010). Police organization continuity and change: Into the twenty-first century. Crime and Justice, 39(1), 55-144.

Mastrofski, S., Parks, J., Reiss, A., Worden, R., DeJong, C., Snipes, J., \& Terrill, W. (1998). Systematic observation of public police: Applying field research methods to policy issues (Report No. NCJ 172859). Washington, D.C: National Institute of Justice. Retrieved from https://www.ncjrs.gov/pdffiles/172859.pdf

McLuhan, M. (1964). Understanding the media: The extension of man. New York, NY: McGraw Hill.

Meehan, A. J. (1998). The impact of mobile data terminal (MDT) technology on communication and recordkeeping in patrol work. Qualitative Sociology, 21, 225-254.

Meijer A., \& Thaens, M. (2013). Social media strategies: Understanding the differences between North American police departments. Government Information Quarterly, 30, 343-350.

Mesa Police Department (MPD). (2013). On-officer body camera system: Program evaluation and recommendations. Mesa, AZ: Mesa Police Department.

Miles, M., Huberman, A., \& Saldaña, J. (2014). Qualitative data analysis: A methods sourcebook. Washington, DC: Sage.

Miller, L., Toliver, T., \& and Police Executive Research Forum (PERF). (2014). Implementing a body-worn camera program: Recommendations and lessons learned. Washington DC: Office of Community Oriented Policing Services.

Muhr, T. (1991). Atlas.ti: A prototype for the support of text interpretation. Qualitative Sociology, 14(4), 349-371. doi:10.1007/BF00989645

Ortiz, M. J. (2018). Gangs and environment: A comparative analysis of prison and street gangs. American Journal of Qualitative Research, 2(1), 97-117.

Patton, M. (1987). How to use qualitative methods in evaluation. Thousand Oaks, CA: Sage Publications.

Pew Research Center. 2017. Behind the Badge: Amid protests and calls for reform, how police view their jobs, key issues and recent fatal encounters between blacks and police. Retrieved from http://www.pewsocialtrends.org/2017/01/11/police-views-public-views (Accessed September 3, 2017)

President's Task Force on 21st Century Policing. (2015). Final report of the president's task force on 21 st century policing. Washington, DC: Office of Community Oriented Policing Services.

Ready, J., \& Young, J. (2015). The impact of on-officer video cameras on police-citizen contacts: Findings from a controlled experiment in Mesa, AZ. Journal of Experimental Criminology, 11(3), 445-458.

Reaves, B. A. (2015). Local police departments, 2013: Personnel, policies, and practices. Washington, DC: Bureau of Justice Statistics.

Rogers, E. M. (2003). Diffusion of Innovations $\left(5^{\text {th }}\right.$ ed). Free Press: New York, NY. 
Rossi, P. Lipsey, M, Freeman, H. (2004). Evaluation: A Systematic Approach. Sage Publications. Thousand Oaks, CA

Schafer, J. A., \& Mastrofski, S. D. (2005). Police leniency in traffic enforcement encounters: Exploratory findings from observations and interviews. Journal of Criminal Justice, 33(3), 225-238.

Scheindlin, S.A., \& Manning, P. K. (2015). Will the widespread use of police body-worn cameras improve police accountability? Americas Quarterly, 9(2), 24-27.

Sherman, L. W. (2013). The rise of evidence-based policing: Targeting, and tracking. Crime and Justice, 42(1), 377-451.

Skogan, W. G. (2005). Citizen satisfaction with police encounters. Police Quarterly, 8, 298-332.

Strauss, A., \& Corbin, J. (1998). Basics of qualitative research techniques. Thousand Oaks, CA: Sage Publications.

Strom, K. (2017). Research on the impact of technology on policing strategy in the 21st century, final report. Washington DC: U.S. Department of Justice.

Tankebe, J., \& Ariel, B. (2016). Cynicism towards change: The case of body-worn cameras among police officers. Hebrew University of Jerusalem legal research paper (No. 16-42). Retrieved from https://ssrn.com/abstract=2850743

Taylor, E., Lee, M., Willis, M., \& Gannoni, A. (2017). Police detainee perspectives on police bodyworn cameras. Trends \& issues in crime and criminal justice, 537, 1-14.

Todak, N., Gaub, J. E., \& White, M. D. (2018). The importance of external stakeholders for police body-worn camera diffusion. Policing: An international journal, 4, 448-464.

U.S. Department of Justice, Federal Bureau of Investigation. (2015). Uniform Crime Reports: Crime in the United States Washington, D.C.

Voigt, R., Camp, N. P., Prabhakaran, V., Hamilton, W. L., Hetey, R. C., Griffiths, C. M., Jurgens, D., Jurafsky, D., \& Eberhardt, J. L. (2017). Language from police body camera footage shows racial disparities in officer respect. Proceedings of the National Academy of the Sciences of the United States, 114(25), 6521-6526. doi:10.1073/pnas.1702413114

White, M. D. (2014). Police officer body-worn cameras: Assessing the evidence. Washington, DC: Office of Community Oriented Police Services.

White, M. D., \& Coldren, J. (2017). Body-worn police cameras: Separating fact from fiction. PM Magazine. Retrieved from http://icma.org/en/press/pm_magazine/article/107941

Willis, J. (2019). Police technology. In The Handbook of Social Control, M. Deflem (Ed.). doi:10.1002/9781119372394.ch16

Willis, J. Koper, C., \& Lum, C. (2018) Technology use and constituting structures: Accounting for the consequences of information technology on police organisational change. Policing and Society. doi:10.1080/10439463.2018.1557660

Willis, J., \& Mastrofski, S. D. (2017). Controlling police through a balance of forces: The case of body cameras. Cahiers de la sécurité et de la justice, 40.

Willis, J., Mastrofski, S. D., \& Weisburd, D. (2004). COMPSTAT and bureaucracy: A case study of challenges and opportunities for change. Justice Quarterly, 21(3), 463-496.

Willis, J., Mastrofski, S. D., \& Weisburd, D. (2007). Making sense of Compstat: A theory-based analysis of organizational change in three police departments. Law \& Society Review, 41, 147-88.

Willis, J.J., and Mastrofski, S.D., 2016. Improving policing by integrating craft and science: What can patrol officers tech us about good police work? Policing and Society. doi: 10.1080/10439463.2015.1135921 
Manuscript received June 17, 2019

Final revision received September 12, 2019

Accepted December 01, 2019 